\title{
APPLiCATION OF MOLDFLOW SimUlation in InJeCtion Molding of Plastic Tank
}

\author{
Piotr Tutak \\ IT Instytut, Społeczna Akademia Nauk, Łódź, Polska \\ piotrtutak@wp.pl
}

\begin{abstract}
This article presents an application of moldflow simulation to optimize the injection molding process of charge air cooler plastic tank. The work shows the advantages of this kind of simulation software and information that it can provide. It also explains how big role today play simulation softwares and how they can improve product and reduce development cost.
\end{abstract}

Key words: simulation, moldflow, tank, charge air cooler, injection molding

\section{Introduction}

Engineering constructions during everyday use are subjected to various types of load, therefore before releasing a design for serial production at first it must be validated to ensure that it fulfills all required functions and it does not pose a threat to a user. This kind of validation usually involves performing a series of physical tests reflecting the phenomena that may occur during use in a given design. However, before building a prototype it is necessary first to check the concept itself. This can be done by experimental research which already require building expensive prototypes at this stage or to calculate rightness of the concept by means of theoretical methods: analytical or numerical. Experimental analysis in which the prototype is built is timeconsuming and very expensive. This is particularly evident when various test variants of a given design concept are tested during the experimental test. Theoretical researches rely on the formulation of the corresponding mathematical description and then solution of such defined task. In case of analytical method for most cases it is difficult to get the exact solution. Such restrictions have forced the development of various numerical methods. At present, most of the calculations for structural engineering issues are done by using computer algorithms based on approximate methods, implemented in the form of programs written in different programming languages. Today 
thanks to the easy algorithmization of approximation methods and the development of computer capabilities in recent years it is possible to perform computer simulations and obtain unattainable results of calculations for a given design concept and then optimize it from virtual validation level without the need of building expensive prototypes.

In the case of a charge air cooler (Figure 1) there are two types of computer simulations which are performed to validate the mechanical strength of this heat exchanger and also its tanks.

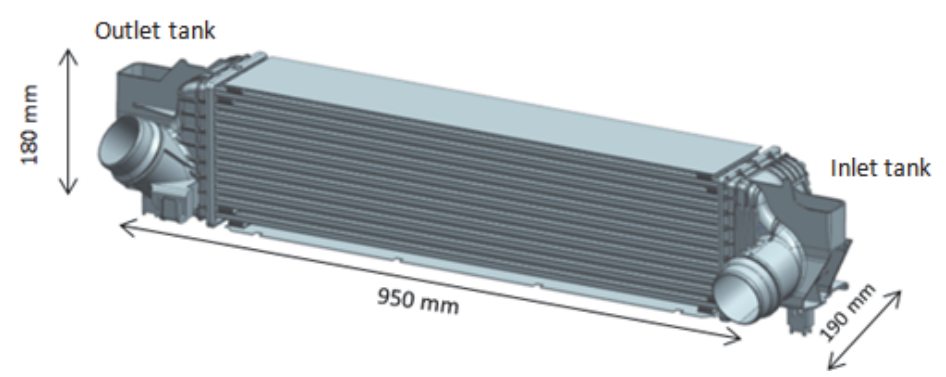

Figure 1. Charge Air cooler [own work]

One of them is a pressure cycle test simulation (Figure 2) checking resistance of its aluminum core and plastic tanks for sinusoidal changing hot air pressure in system. The pressure cycle test consists of applying cyclically changing air pressure provided to the inlet system of charge air cooler with specific temperature, frequency and through defined quantity of cycles. The test result is considered as positive if the leak level after test is in a given specification limit.

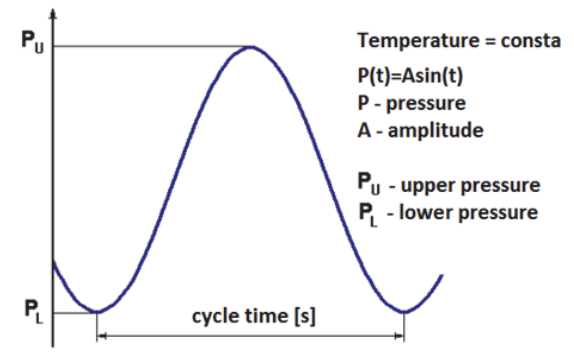

Pressure cycle test specification

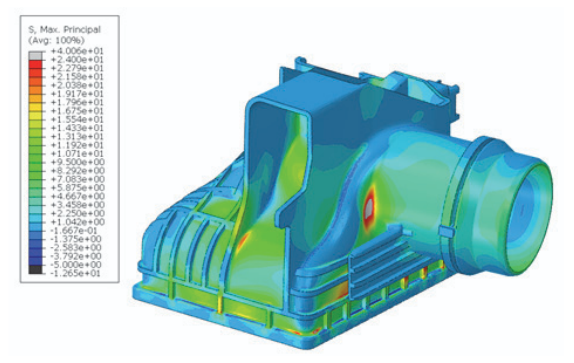

Pressure cycle test FEA stress result

Figure 2. Pressure cycle test [own work]

In this article we will focus on a second simulation, called moldflow which validates the design of the charge air cooler's tank from the injection mold level. Not only is the moldflow used to support and optimize the work of 
plastics parts designers but also injection mold designers and injection molding technologists.

\section{Moldflow simulation}

Moldflow gives the opportunity of quick assessment of a just designed product at the stage of digital designing, which allows to eliminate all errors at this level. Thanks to moldflow simulation injection molding process has achieved impossible so far level of engineering. Virtual injection trials can be done without the need of building physical models. Figure 3 presents a typical injection molding machine.

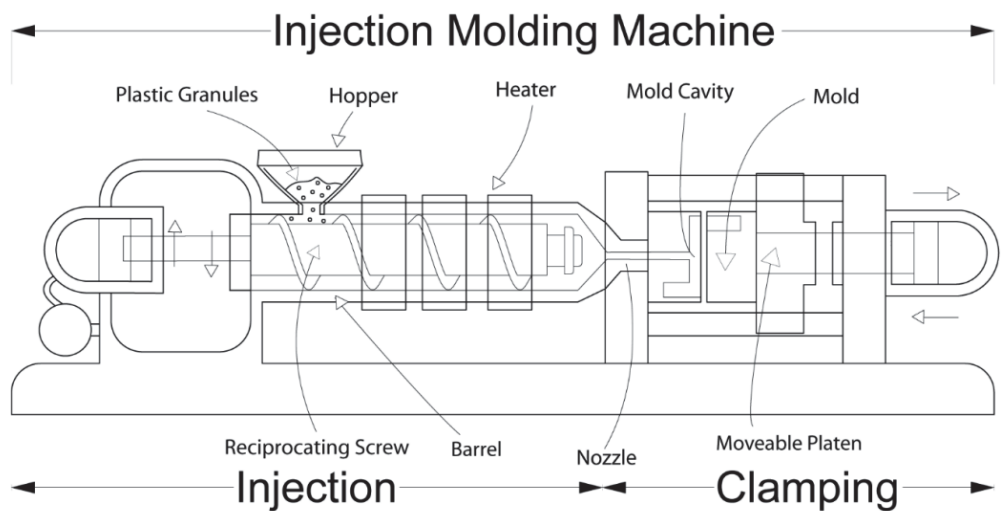

Figure 3. Injection molding machine [Wikipedia]

Table 1 shows an exemplary set of questions for which a group of engineers need to find answers to produce an optimized product. The moldflow simulation allows to find answers for these questions without the additional cost of building or modifying a prototype.

Table 1. Modlflow simulation feedback [own work]

\begin{tabular}{|l|l|l|}
\hline \multicolumn{1}{|c|}{ Part designer } & \multicolumn{1}{c|}{ Mold designer } & \multicolumn{1}{c|}{ Injection technologist } \\
\hline - which material is optimal & - is cooling optimal & - is injection pressure proper \\
\hline - is wall thickness correct & - where inlet of cooling should be placed & - what is the filling and clamp profile \\
\hline - what will be deformation of part & - should channels be heated & - what are the machine settings \\
\hline - cold or hot channels system & - are channels balanced & - is process stable \\
\hline - will be cavity filled & - is BeCu insert necessary & - has been quality level reached \\
\hline - where will be the weld lines & - where cavity degassing system should be placed & - can be cycle time reduced \\
\hline
\end{tabular}


Below there is a moldflow simulation of injection molding process executed to validate charge air cooler's inlet tank mold.

Figure 4 presents an object of simulation, the 3D model of charge air cooler's inlet tank, marked in green. The red rod is the injection nozzle through which material under pressure is provided to the mold. The performed simulation provides information on the influence of the assumed injection point position on the key parameters of the process.

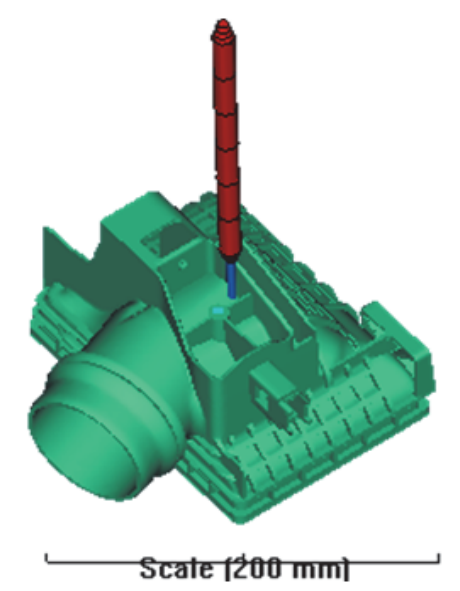

Figure 4. Inlet tank model (green) with injection nozzle (red) [own work]

Figure 5 shows the temperature of the material stream face during mold filling. Based on this result we can see that the mold filling process is correct because the material temperature is almost the same in the entire area.
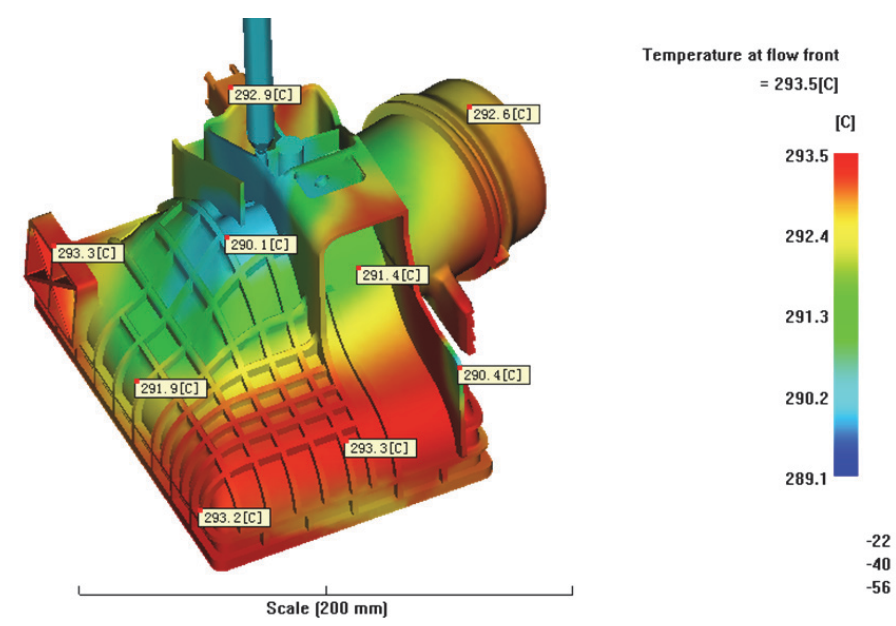

Figure 5. Temperature of material stream face [own work] 
Figure 6 shows temperature distribution in the tank after material injection. Based on this we can see that temperature of the mold is heterogeneous what can result in uneven shrinkage of the material what in turn may cause significant deformation of such injected tank.
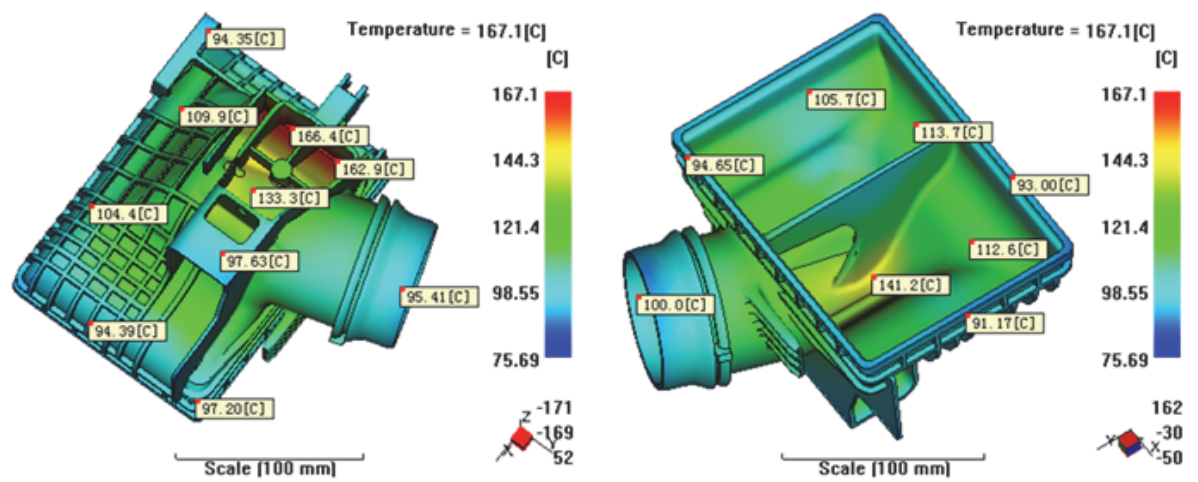

Figure 6. Temperature of tank after injection [own work]

To compensate the effect of uneven temperature distribution of mold, a cooling system needs to be implemented. In case of polyamide tanks the operating medium in cooling system is water. Mold temperature can be controlled by diameters of the cooling channels, their location in the mold as well as water pressure and its temperature, which for products made of polyamide should be approximately $80^{\circ} \mathrm{C}$. Designed and analyzed cooling system is shown in Figure 7. It meets all requirements for cavity temperature (moving part of the mold on the clamp side) as well as the core temperature (stationary part of the mold on the injection side).
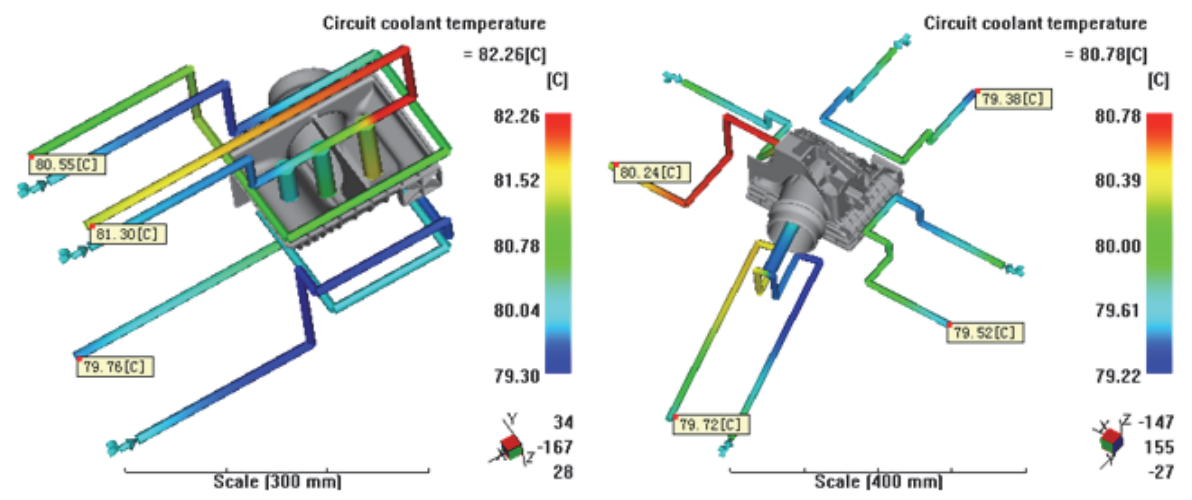

Figure 7. Designed cooling system [own work] 
Moldflow analysis allows to specify the duration time of the injection process. The filling time for the analyzed tank is 2.047 seconds (Figure 8), where about $98 \%$ of the material is applied to the mold. Simulation also provides information on how the material flows and where it flows at the end, in this case it is the pipe and the tank foot area.

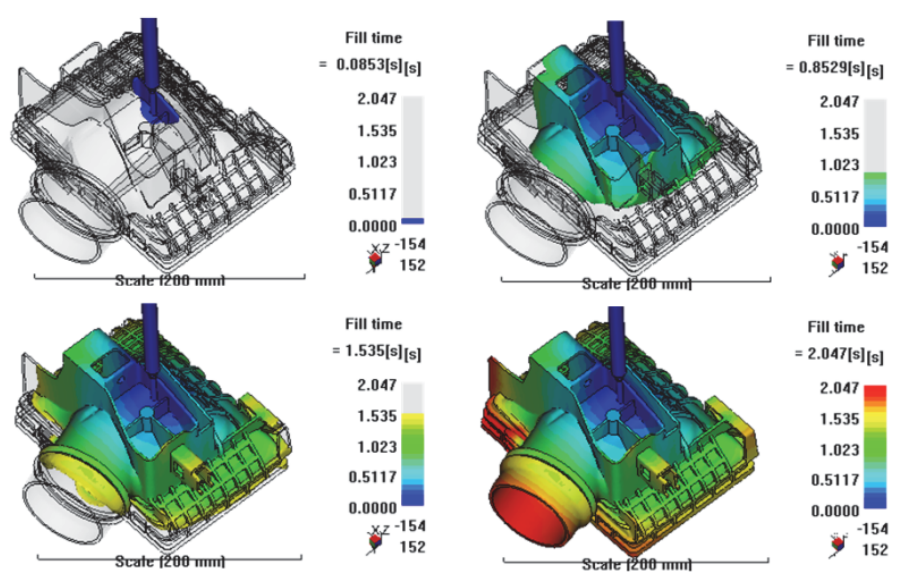

Figure 8. Mold filling phase [own work]

Based on the simulation result the required pressure value at the injection point has been defined as $30.1 \mathrm{MPa}$ (Figure 8) and the duration of the phase 15.5 seconds during which $2 \%$ of the missing material is pressed. In addition, the program provides also the value of clamp force 88 tons (Figure 9) which ensures that the mold does not open during the material injection.

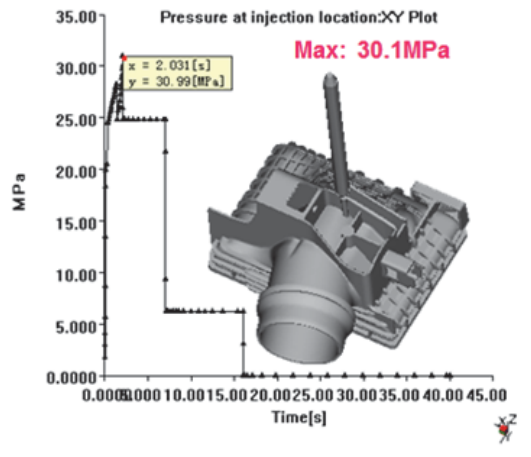

Figure 8. Required pressure in the injection point [own work]

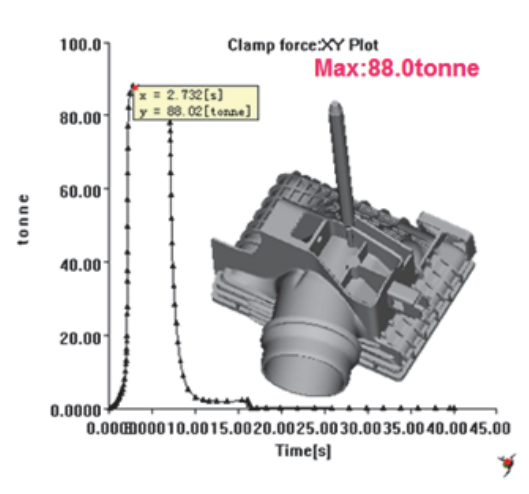

Figure 9. Required clamping force [own work] 
The moldflow analysis also shows the orientation of glass fibers in the tank (Figure 10). Glass fibers in terms of strength for tank play a similar role like steel reinforcement in concrete used in construction constructions. Depending on the orientation of these fibers, there is a different shrinkage of material that affects the final shape of the product and its dimensions. When the fibers are stacked in parallel, the shrinkage in this area is about $0.5 \%$ but when fibers are perpendicular to each other, the shrinkage is about $1-1.5 \%$ to the initial length. The orientation of glass fibers is defined by the direction of the material flow during injection. If the analysis shows an aggregation of fibers in a given area (Figure 11) then such a place is characterized by worse strength properties and a tank's crack can occur in this place.

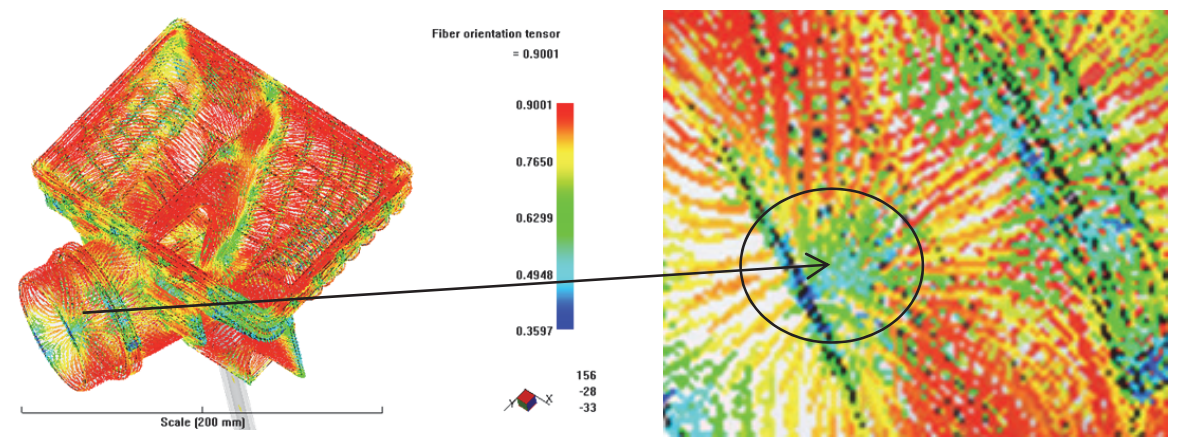

Figure 10. Orientation of glass fibers in tank [own work]

Figure 11. Aggregation of glass fibers [own work]

Another issue with negative impact on the mechanical strength of the injected parts is the fact of arising during the injection process weld lines. They are formed as a result of merging the faces of the two material streams coming from different directions having different temperature (Figures 1213). If the injection process is well set the weld lines are not visible. 


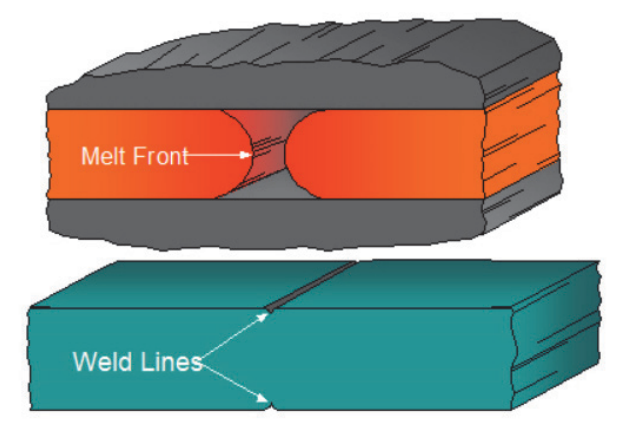

Figure 12. Weld line formation [www.mapeng.net]

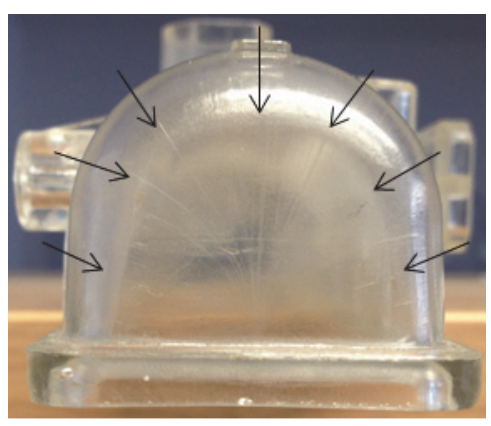

Figure 13. Weld lines [own work]

Moldflow tool for cavity filling process indicates where the potential locations of the weld lines could occur and how large they could be (Figure 14-15).
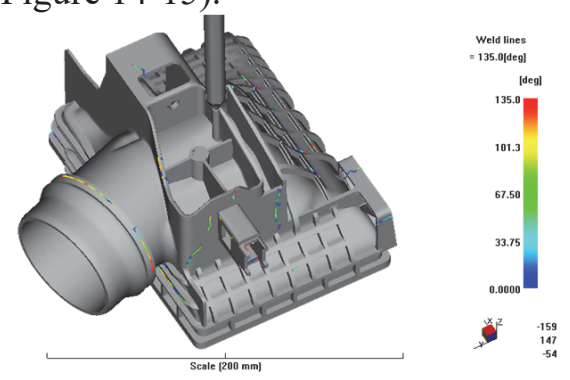

Figure 14. Weld lines location [own work]
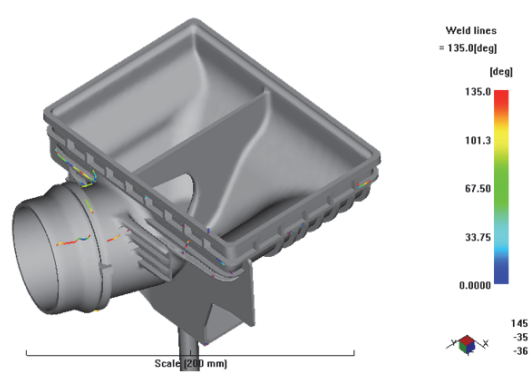

Figure 15. Weld lines location [own work]

This tool allows to verify if weld lines are located in the area where potential crack might occur. From the material durability point of view this kind of weld lines cause local weakness in the place of their occurrence. Based on weld lines location and pressure cycle simulation result decision is taken if a weld line in a given position is acceptable or not. If pressure cycle test simulation shows that in the area where the weld line is located there is also concentration of stress, the risk of crack in this area is very high. Moldflow provides also information about the deformations that may occur in the tank after injection. Figure 15 shows the final deformation of the analyzed tank in all directions. 

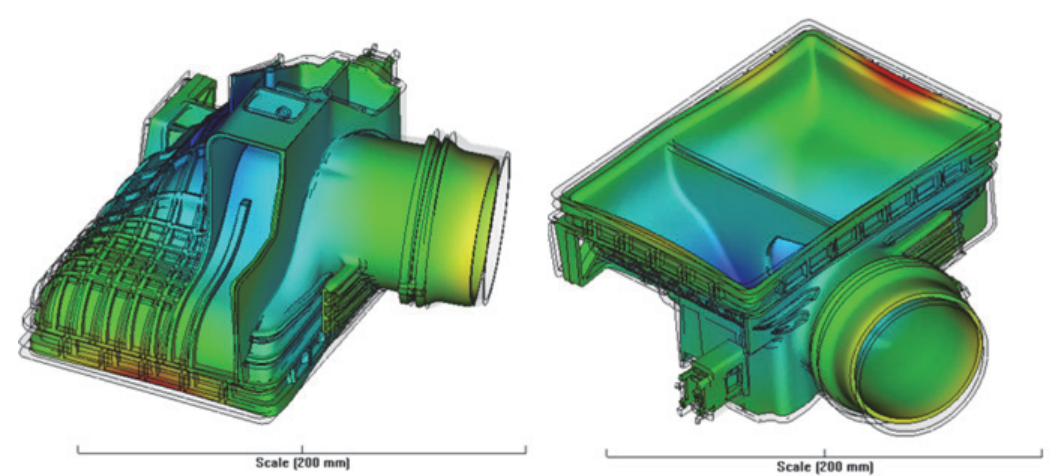

Figure 15. Tank deformation [own work]

The program also calculates the duration of each phase which is necessary to estimate the total cycle time.

\section{Conclusion}

This article presents an application of computer simulation optimizing the injection molding process based on the example of charge air cooler plastic tank. The presented moldflow analysis of the tank shows how important role simulation programs play today. So far, it was impossible to obtain the results of calculations for a given design concept. Now, by means of moldflow program optimization can be done from virtual validation level without the need of building expensive prototypes. It allows to create the most optimal products with minimal effort, improve quality, reduce development cost and control one of the most difficult technological processes, the injection molding process.

\section{References}

1. Aliabadi M., Brebbia C.A., Computational methods in contact mechanics, CMP and Elsevier Applied Science, London, 1992

2. Basmadjin D., The Art of Modeling in Science and Engineering, Chapman\&Hall-CRC, 1999.

3. Champion E.R., Finite Element Analysis in Manufacturing Engineering, McGraw-Hill, New York, 1992.

4. Crandall S.H., Engineering Analysis, McGraw-Hill, New York, 1956

5. Huebner K.H., The Finite Element Method for Engineers, Wiley, New York, 1975. 
6. Jenkins W.M., Matrix and Digital Computer Methods Structural Analysis, McGraw-Hill, New York, 1969.

7. Taler J.,Teoria i praktyka identyfikacji procesów przepływu ciepła, Ossolineum, Warszawa-Kraków-Wrocław, 1995.

8. Yang T. Y., Finite element structural analysis, Prentice Hall, New York, 1986.

9. www.autodesk.com, access 27.09.2017

10. www.robobat.pl, access 28.08.2017

11. www.pccpolska.pl, access 11.08.2017

12. www.ascented.com, access 27.08.2017

13. www.mat.net.pl, access 22.08.2017

14. www.moldmakingtechnology.com, access 22.09.2017

15. www.plasticstoday.com, access 22.08.2017 